\title{
Fluorescent Protease-activated Peptide AVB-620
}

National Cancer Institute

\section{Source}

National Cancer Institute. Fluorescent Protease-activated Peptide AVB-620. NCI

Thesaurus. Code C121545.

A protease-cleavable peptide linked to a fluorescent probe, with potential imaging activity. Upon intravenous infusion of the fluorescent protease-activated peptide AVB620 before surgery, the peptide moiety of AVB- 620 can be cleaved by proteases overexpressed by tumor cells. This activates the fluorescent probe and the tumor cells expressing the proteases can be detected using a fluorescence imaging system. This allows for the visualization and removal of the tumor during surgery. 